\title{
Using High-Speed Camera to Investigate Failure Waves in K9 Glass
}

\author{
Jianheng Zhao ${ }^{1,2}$, Chengwei Sun ${ }^{1,2}$, Zhuping Duan', \\ Xianxiang Tan ${ }^{1}$, Feng Zhao' and Sanggang Wen ${ }^{1}$ \\ ${ }^{1}$ Institute of Fluid Physics, PO Box 919-113, Mianyang, Sichuan 621900, China P.R. \\ ${ }^{1}$ Institute of Mechanism, Chinese Academy of Sciences, Zhongguancun, \\ Haidian, Beijing 100080, China P.R.
}

Keywords: Detonation, Failure Wave, High-Speed Shadowgraph Technique

\begin{abstract}
The high-speed shadowgraph technique was used in visualization of the shock wave moving, damage formation and development in the glass specimen. It is found that failure wave formed at the shocked surface and inner interface, and propagated into specimen following the shock wave. It is concluded that formation of failure wave was connected with the surface of glass-specimen, and it is a moving fractured front. The work finished here will be helpful to understand the mechanism of failure wave.
\end{abstract}

\section{Introduction}

When Rasorenov and G.I.Kanel[1] researched the dynamic response of K19 glass specimen under shock loading by detonation in 1991, they found that there exists a small recompression signal in the record of rear free-surface velocity of the specimen using VISAR. They conjectured that there must have been a moving front at the velocity of $1.5-2.5 \mathrm{Km} / \mathrm{s}$ following compressive wave to propagate into the specimen, behind which the material is comminuted, and has a lower impedance and no tensile strength. This moving front was called by them as failure wave. Many researchers devoted their much efforts to this subject in recent years. But until now, failure wave was only observed in glass-like brittle materials with higher compressive strength and lower density than metals, and its mechanism is far from clear. Kanel[1], He Hongling[2] and Zhang Guanren[3] speculated on that the mechanism of failure wave connected with the micro-cracks on the surface of specimen. The experiments of different impact surface roughness can be used to test this speculation correct or not. Unfortunately, There are contrary experimental results about this topic from two independent experiments[4,5]. R.J.Clifton[6] presented a phase transformation model, 
attempting to explain the mechanism of governing the generation and propagation of failure wave. This model can explain many experimental phenomena, but until now, no experiments can testify the relation between failure wave and phase transformation. Grady[7] put forwarded a shear failure model, his model also meet disputable points in contrary to explain the experimental observation. In this paper, we attempted to visualized the failure wave formation at the shocked surface and inner-interface of $\mathrm{K} 9$ glass specimens, and attempt to understand the mechanism of failure wave formation.

\section{Experiment setup}

Fig.1 shows the experimental setup. The detonation device of planar wave consist of detonator 10 , booster 11 and planar wave lens12. In the experiment, it takes only $1.42 / 1.45 \mu$ s to detonate the detonator 10. It is very important to control the synchronization of the system. The pressure behind the detonation wave is $10.78 \mathrm{GPa}$ before detonation wave arrive at the end of the planar wave lens. Copper plate 13 is used to let loading stress in K9 glass specimen smaller than its Hugoniot elastic limits(HEL). Table 1 shows experimental conditions.

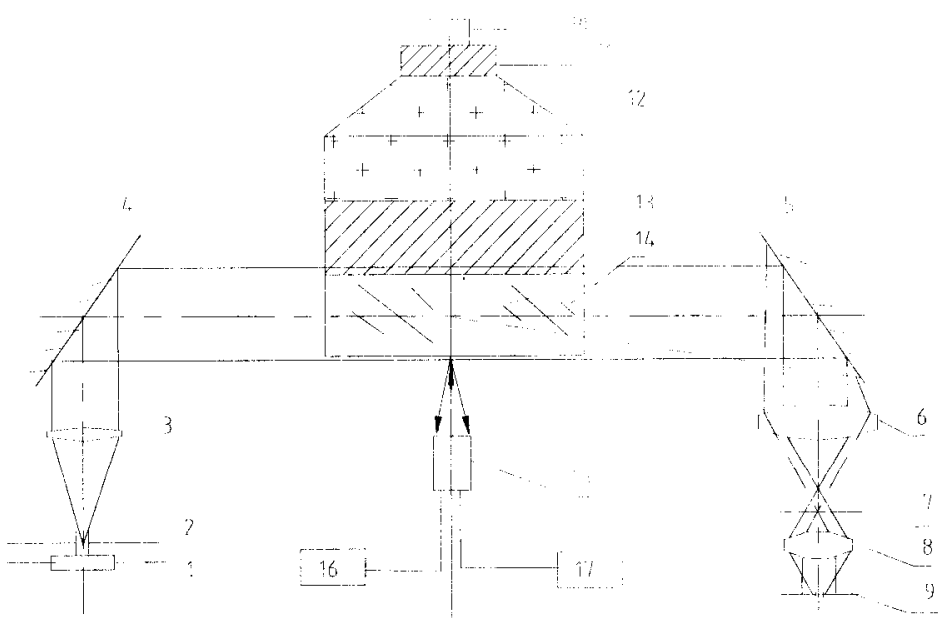

Fig. 1 Experimental setup

1. Xenon discharge tube, 2. Iight aperture, 3. illuminating lens, 4, 5.mirror 6. First object lens 7. graticule, 8. first group of second ob ject lenses. 9. first frame aperture of camera, 10. detonator, 11. Booster, $12 \mathrm{planar}$ wave lens

13. attenuation plate, 14. $\mathrm{K} 9$ glass specimen, 15, VISAR probe, 16. Iaser, 17. VISAR

表2-1 Loading condition

\begin{tabular}{|c|c|c|c|}
\hline No. & $\begin{array}{c}\text { Thickness of } \\
\text { copper plate } / \mathrm{mm}\end{array}$ & $\begin{array}{c}\text { Loading } \\
\text { stress in K9 } \\
\text { glass/ GPa }\end{array}$ & $\begin{array}{c}\text { Thickness of } \\
\text { K9 specimen } \\
/ \mathrm{mm}\end{array}$ \\
\hline 1 & $\mathrm{Cu} \mathrm{19}$ & 8.26 & 24 \\
\hline 2 & PMMA $(10)+\mathrm{Cu}(18)$ & 5.89 & $6.5+24$ \\
\hline
\end{tabular}


The K9 glass specimen was cut from $24 \mathrm{~mm}$ or $6.5 \mathrm{~mm}$ thick sheets into $120 \times 120 \mathrm{~mm}^{2}$, each surface of specimen was polished. The density of $\mathrm{K} 9$ glass is $2.52 \mathrm{~g} / \mathrm{cm}^{2}$, Young's modulus $E=47.14$ $\mathrm{GPa}$, HEL is $8.4-9.16 \mathrm{GPa}$, Poisson rate $v=0.209$, and the longitudional sound velocity is $C_{l}=6.06$ $\mathrm{km} / \mathrm{s}$.

The optical path of shadowgraph 1-9 used in experiment is shown in Fig.1. Xenon discharge tube is located at the focus of illuminating lens 3 . When the light from Xenon discharge tube 1 pass through light aperture 2 and lens 3 , it will be parallel to illuminate the specimen 14 . The specimen 14 is first imaged at the graticule 7 by lens 6 . The grating of the graticule can be used to quantificationally analyze. The graticule 7 is imaged on negative by lens 8 and framing lens of high-speed camera. When the refractive index in the specimen under shock loading change, it will induced the light through the specimen deflection, and lead to change of intensity of illumination on the negative. This is the working principle of shadowgraph technique.

The high-speed camera used in the experiments was FJZ 250. Its exposure time for each frame is $100 \mathrm{~ns}$, interframe time is $400 \mathrm{~ns}$, and forty frames can be recorded. The magnification of the shadowgraph system is 0.28 . The field of view of this system is $74 \times 54 \mathrm{~mm}^{2}$. Its spatial resolution is about $24 \mathrm{lp} / \mathrm{mm}$. The most of the parameters in this system is better than Bourn: $\mathrm{s}[8]$.

3. Experimental results and analysis

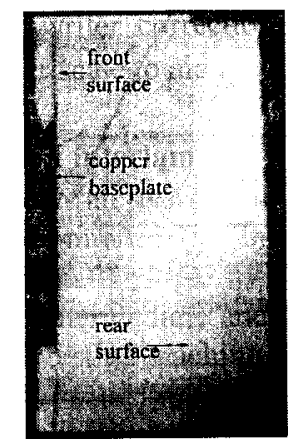

- (1) $0 \mu \mathrm{s}$

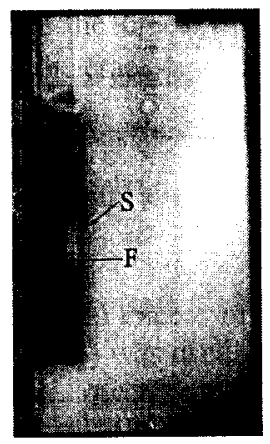

(2) $1.2 \mu s$

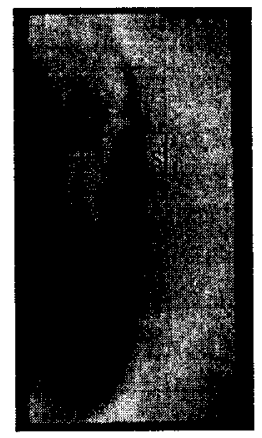

(3) $3.6 \mu \mathrm{s}$

Fig. 2 Framing camera pictures of $\mathrm{K} 9$ glass specimen $24 \mathrm{~mm}$ thick under detonation loading

Fig.2 shows the experimental records of No.1. The figure 2(1) is the frame in which shock wave still not propagate into glass specimen. We can found the surfaces of the specimen. The black area at the left of this frame is one part of copper plate. From Fig2(2) and (3), it is found a black shadow move into the specimen, and divided into two parts. One moves more quickly than another, and the velocity of the faster one is $5.8 \pm 0.2 \mathrm{~mm} / \mu \mathrm{s}$. Its front is obviously shock wave. The front of the second shadow area is irregular, Bourne[8] speculated the irregular front is caused by cracks. It can deduced its average velocity is about $1.8 \pm 0.5 \mathrm{~mm} / \mu \mathrm{s}$ based its position in each frame and interframe time. Figure 3 shows the relation of velocity of rear free surface of $8.1 \mathrm{~mm}$ thick $\mathrm{K} 9$ glass specimen vs. time under the same loading condition as No.1. It is obviously failure wave formed in K9 glass specimen $8.1 \mathrm{~mm}$ thick because there is a small velocity increase on this profile, and its velocity is $1.342 \mathrm{~mm} / \mu \mathrm{s}$. This slow moving front of shadow in fig. 2 is so called failure wave, because its 
velocity is almost same as that failure wave got by VISAR in Fig. 3 , It is found there are irregular shadow stripes behind the shock wave front. They appear in the frame, and disappear or change in the next frame. These stripes are caused by the triangle spatial profile of pressure behind shock front. When the pressure behind shock wave changed, and lead to variety of refractive index .

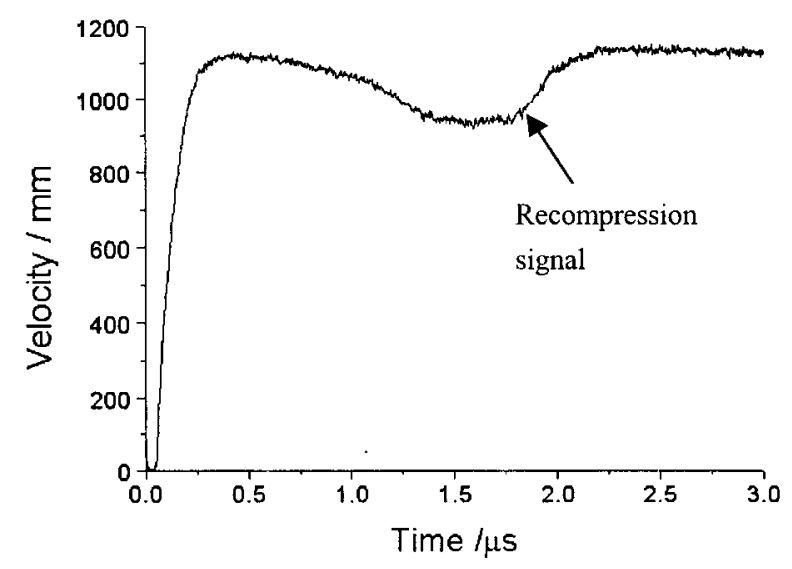

Figure 3 The velocity of rear free-surface of $8.1 \mathrm{~mm} \mathrm{K9}$ glass specimen vs. time under detonation loading

Figure 4 shows the frames of double glass specimens under detonation loading. Specimen $A$ is 6.5 $\mathrm{mm}$ thick, Specimen $\mathrm{B}$ is $24 \mathrm{~mm}$. Both of these specimens are clung together. The maximum stress in specimen is $5.89 \mathrm{GPa}$ in No.2 experiment. In fig.4(2), the shadow moved into specimen A from left at $0.4 \mu \mathrm{s}$, and is also divided into two parts in figure4(3) at $0.8 \mu \mathrm{s}$, which is same as that of figure 2. It is of course the first one is shock wave, and the second one is failure wave. In fig.3 (4) we can find another black region form at the inner interface between the two specimen at $16 \mu \mathrm{s}$. This black region developed, and moving with velocity $1.6 \pm 0.5 \mathrm{~mm} / \mu \mathrm{s}$ behind shock front in the next frames, and its front is same as that of the failure wave in specimen A. This indicates the front of this black region is another failure wave, which formed at the interface of two specimens. It is difficult to say the mechanism of failure wave contacted with the micro-cracks on the surface of specimen or phase-transformation on the base of the failure wave formed at the impacted surface. But it can be concluded that failure wave contacted with the surface of glass specimen according to the experimental frame that another failure wave formed at the inner-interface of two glass specimens. Because if failure wave is phase-transformation wave, it ought to propagated into specimen from impacted surface into specimen, how to explain the second phase-transformation wave form at the inner-interface in the front of the first one at the same loading condition for same material. That authors reckon the formation of failure wave is contacted with the special structure of surface of glass specimen are on the base of following reasons. (1) Because the failure wave is formed at surface and inner-interface of specimens under shock wave loading, the failure wave must contacted with the surface of glass specimen. (2) The structure of surface is different from the inner for glass specimen. (3) Each surface of glass specimen has hundreds or thousands of micro-cracks per square centimeter when they were polished, even for the optical surface. The exist 
of these micro-cracks lower the strength of surface of glass specimen. These micro-cracks were activated and developed into the specimen when the pressure is higher enough. When they propagated into specimen, their front is the failure wave because dynamic impedance behind of this front is lower than that in front of this front due to material comminuted.

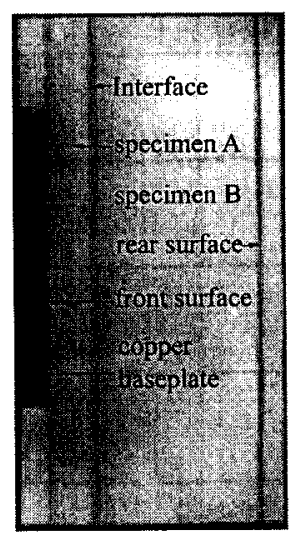

(1) $0 \mu s$

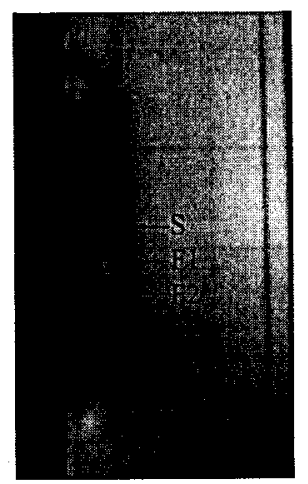

(4) $1.6 \mu \mathrm{s}$

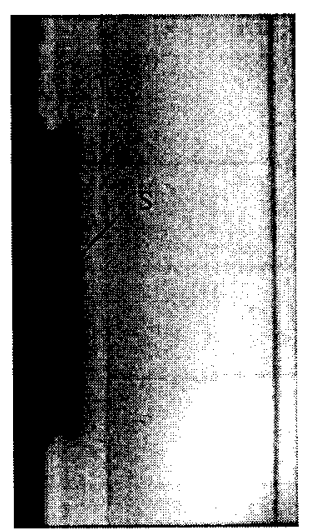

(2) $0.4 \mu s$

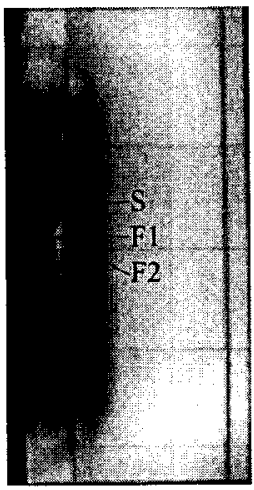

(5) $2.0 \mu$

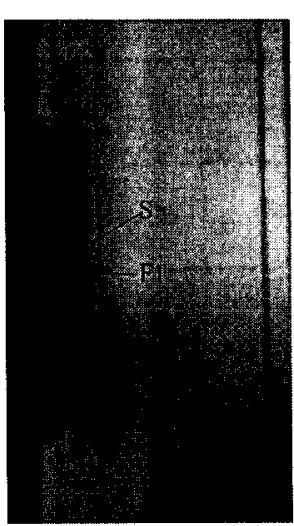

(3) $0.8 \mu s$

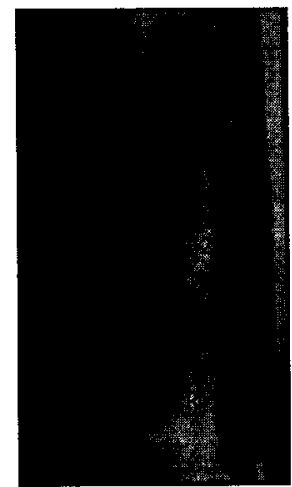

(6) $6.4 \mu \mathrm{s}$

(F1-Failure wave 1, F2-Failure wave 2, S-Shock wave, R-release wave)

Fig. 4 Framing camera pictures of double specimens of K9 glass under detonation loading

4 Conclusion

Failure wave is a moving comminuted front. Its formation is connected with special structure of glass specimen and the micro-cracks on the surface.

\section{Reference}

1.S.V.Rasorenov, G.I.Kanel ,V.E.Fortov and M.M.Abasehov, High Pressure Research, Vol.6. (1991),p.225-232,

2. Zhang Guanren, Chinese Journal of high pressure physics, , 10(1997),p.1 
3. He Hongliang, dynamic response and microstructure damage of brittle materials under shock wave loading. A dissertation inpartial fulfilment of requirements for the degree of PH.D, Southwest Institute of fluid physics, 1997.

4.Neil Bourne, J.Appl.Phys. Vol 81(1997),p.6670-6674,

5.G.F. Raiser, et.al. D.E. Grady and D.E.Cox, J.Appl. Phys. 75 (1994), p.3862-3870

6.R.J. Clifton, Appl. Mech. Rev. 46(1993),p.540-546

7.D.E. Grady , NTIS, 1994

8.N.K.Bourne et. al.,Journal De Physique IV,Vol.4 ,Colloque C8,(1994),p. 635-640, 
Fracture and Strength of Solids IV

10.4028/www.scientific.net/KEM.183-187

Using High-Speed Camera to Investigate Failure Waves in K9 Glass

10.4028/www.scientific.net/KEM.183-187.343 